\title{
A parábola como recurso formal: um estudo sobre o mito de Joana D'arc em Paul Claudel e Bertolt Brecht
}

ANA CAROLINA PAIVA ${ }^{1}$

\footnotetext{
1 Atriz e pesquisadora. Graduada em Interpretação Teatral pela Faculdade de Artes Dulcina de Morais (1997), tem mestrado em Teatro pela Universidade Federal do Estado do Rio de Janeiro - Uni Rio (2002), Doutora em Artes Cênicas pela Universidade Federal do Estado do Rio de Janeiro - Uni Rio, com tese defendida em 2009, com orientação da profa Dra. Evelyn Furquim Werneck Lima. Email: carolina.paiva@yahoo.com.br
} 


\section{- RESUMO}

O mito criado a partir da história da francesa Joana d'Arc exerceu grande fascínio em diversos autores de teatro, e sua história tem sido recontada e representada até os dias de hoje. Alguns autores construíram caminhos alternativos para a sua criação dramatúrgica que foram além da perspectiva histórica e realizaram verdadeiras "adaptações" para locais, épocas e linguagens diferentes, percorrendo variadas formas de trabalhar o arquétipo da virgem francesa. Esta forma de contar uma história nos remete à ideia de construção dramatúrgica através da parábola, em que uma ou várias mensagens são superpostas de maneira oculta dentro da narrativa principal. Brecht e Claudel criam imagens que são capazes de compor os sentidos possíveis que possam ser dados a este mito, lançando um olhar sobre o passado, porém considerando sempre o panorama atual. Os autores procuraram captar os conteúdos ideológicos e ontológicos que se encontravam além da perspectiva histórica e mitológica. Quando os próprios autores se permitem lidar livremente com a história, trazendo para o tempo presente um evento passado, possibilitam que haja uma reciclagem neste evento e consequentemente este passado vem à tona, ainda que carregado de criações não verídicas. Desta forma o passado não desaparece, ao contrário, ganha vida e força. Dependendo do que se escreve e da forma como se escreve, é possível se estabelecer pontes com o presente, ainda que se esteja lidando com um fato histórico.

\section{- PALAVRAS-CHAVE}

Parábola, dramaturgia, convenção.

\section{- ABSTRACT}

The myth created from the history of French Joan of Arc exerted great fascination on many playwriters and her story has been retold and played up to nowadays. Some authors developed alternative ways to create their plays that went beyond the historical perspective, making adjustments for different locations, ages and languages, covering various forms of working the archetype of the French virgin. This form of storytelling brings us to the idea of dramaturgic construction using the parable, in which one or more messages are superposed in a hidden way within the main narrative. Brecht and Claudel create images able to compose the possible directions that can be given to this myth, casting a glance at the past but always considering the current situation. The authors try to capture the ideological and ontological contents that stayed beyond the historical and mythological perspective. When the authors allow themselves to deal freely with history, bringing to the present time a past event, they allow the recycling of this event and therefore this past comes to light even though it may be full of untruthful creations. Therefore the past does not disappear, but instead it comes to life and strength. Depending on what it is written and how it is written, it is possible to build bridges to the present, even if one is dealing with a historical fact.

\section{KEYWORDS}

Parable, dramaturgy, convention.

O mito de Joana d'Arc - a jovem francesa nascida em 1412 e morta em 1431 - a jovem camponesa analfabeta que liderou tropas do sul da França contra a invasão dos ingleses na Guerra dos Cem Anos, condenada a morrer na fogueira pela igreja católica, acusada por crime de heresia e bruxaria -, exerceu grande fascínio em diversos autores de teatro que, contudo, construíram caminhos alternativos para a sua 
criação dramatúrgica. Caminhos que foram além da perspectiva histórica.

O procedimento de contar a história de um personagem real além da perspectiva histórica nos remete à construção parabólica, em que uma ou várias mensagens são superpostas de maneira oculta dentro da narrativa, digamos, imediata.

O interesse por desvendar se a motivação da heroína francesa ao liderar um exército contra a Inglaterra foi de ordem mística e sobrenatural não despertou interesses maiores no dramaturgo francês Paul Claudel, tampouco exerceu interesse por parte do dramaturgo alemão Bertolt Brecht, que escreveram peças utilizando o arquétipo da virgem francesa. Por outro lado, a heroína é vista pelos autores muito mais como um símbolo que pode ser trabalhado em todos os tempos e em todos os espaços e não está preso a convenções formais e a contextos temáticos específicos.

$\mathrm{O}$ que poderia unir dois autores com pontos de vista sobre o mundo tão diferentes? Os autores optam por criarem em suas peças imagens que sejam capazes de compor os sentidos possíveis que possam ser dados a este mito, deixando em aberto a possibilidade de serem descobertos outros sentidos por parte dos leitores e espectadores, procuram captar os conteúdos ideológicos e ontológicos reveladosa partir dos andamentos parabólicos dados à narrativa de suas peças. Assim, lançam seu olhar sobre o passado, sem desconsiderarem o panorama atual. Este tipo de tratamento dado ao tema implicou no não interesse pelo feito heróico em si, e consequentemente no interesse pelos caminhos e significados possíveis, gerados a partir do feito heróico (BORNHEIN, 1992, p. 185).

Optou-se por trabalhar com dois textos de Brecht: A Santa Joana dos Matadouros e As Visões de Simone Machard. Esta opção dupla se deu por conta do autor trabalhar duas interpretações da ideia do mito com pontos de convergência e divergência entre si, mas sem deixar de levar em consideração que Brecht cria seus textos partindo de uma aguçada visão da problemática da divisão de classes dentro das sociedades capitalistas. Tendo em vista os aspectos antagônicos em relação à visão brechtiana, mas levando em conta a semelhança de sua abordagem narrativa, inseriu-se o ponto de vista de Paul Claudel através da peça Joana d'Arc entre as Chamas, que na extensão de toda sua obra dramatúrgica compartilha da filosofia de Tomás de Aquino de que existe um projeto de Deus intrinsecamente bom que é a criação, que o homem teria o poder de reduzir ou obscurecer de acordo com o seu livre-arbítrio (LE GOFF, 2005, p. 141-142).

Ainda que possuam divergências em relação aos pontos de vista ideológicos, Claudel e Brecht "se deixam levar" pela própria narrativa, que em determinado momento se desloca do pensamento dos autores e adquire independência e autonomia. De tal modo, há momentos em que o teatro de Brecht se aproxima do teatro de Claudel e vice-versa, tanto no que diz respeito ao aspecto formal quanto no que diz respeito à temática.

Quando os próprios autores se permitem lidar livremente com a história, trazendo para o tempo presente um evento passado, possibilitam que haja uma reciclagem neste evento. $E$ este passado vem à tona, ainda que marcado por construções não verídicas. Desta forma o passado não desaparece, ao contrário, ganha vida e força. Dependendo do que se escreve e da forma como se escreve, é possível estabelecer pontes com o presente, por mais que se esteja lidando com um fato histórico.

Quando Walter Benjamin discute o conceito de história ele entende que o passado não retorna impunemente e que "somente a humanidade redimida poderá apropriar-se totalmente do seu passado", reiterando que o passado não deverá ser nem 
sequer citado se a humanidade não estiver realmente redimida (BENJAMIN, 1985, p. 223). Do pensamento de Benjamin se infere que somente à arte é dada cumprir o papel de "sujar as mãos" com o passado. E ela teria ainda o poder de construir uma ponte do tempo passado com o tempo presente, tendo em vista o exemplo do caminho que Brecht e Claudel percorrem ao descreverem suas parábolas sobre o mito de Joana d'Arc.

Por intervenção de suas peças, Brecht e Claudel mergulham no passado da personagem real Joana d'Arc e trazem à superfície os vestígios do tempo em que viveu a camponesa e dos tempos que sucederam este tempo, até alcançarem seu próprio tempo histórico. Os vestígios do passado geram apenas reminiscências deste passado, pois como não há mais condições de recuperação de um passado intacto e homogêneo só é possível recuperar uma síntese do passado em forma de reminiscência, que contém a sua cota de veracidade, contudo, é passível de ser "contaminada" pelas recriações populares - em forma de lendas, canções ou mesmo apropriações místicas - além das recriações de cantores, poetas, romancistas e dramaturgos.

Benjamin revela que o indivíduo comum deve se apropriar das reminiscências do passado, sobretudo como ferramenta para reconhecer as marcas do passado que possam ter sido forjadas por um pensamento ideológico dominante.

As considerações de Benjamin em relação às manipulações históricas encontram nas dramaturgias construídas como parábolas mecanismos artificiais (parabólicos), capazes de revelar algumas verdades históricas justamente pelo fato de não se apresentarem de forma realista, mas numa forma alegórica e metafórica que não se compromete em apresentar o fato realisticamente, como um documento. (Pavis, 1999: 276). Trata-se de uma via de mão dupla: a parábola histórica revela o fato real, mas não se revela como uma narrativa real. Ela se "protege" da verdadeira mensagem oculta em si e ao mesmo tempo adquire contornos próprios, torna-se independente do seu conteúdo real. Segundo Pavis:

A parábola não poderia ser, sem perder o encanto, um simples disfarce termo a termo
de uma mensagem unívoca. Deve preservar sempre uma certa autonomia e opacida-
de para significar por si própria, nunca ser totalmente traduzível em uma lição, mas
prestar-se ao jogo da significância e aos reflexos da teatralidade (PAVIS, 1999, p. 276).

Sob estas circunstâncias, o próprio tratamento dado ao mito já apresentou muitas contradições históricas haja vista que por muitos séculos Joana d'Arc foi considerada um símbolo da direita monarquista e só depois da Primeira Guerra Mundial deixa de ser uma heroína da direita e torna-se um símbolo da unidade nacional francesa. Benjamin conclui suas reflexões sobre este tema com as seguintes palavras: "A história é objeto de uma construção cujo lugar não é o tempo homogêneo e vazio, mas um tempo saturado de agoras" (BENJAMIN, 1985, p. 229).

Transferindo-se a ideia contida no conceito de "reminiscência" utilizado por Benjamin em suas teorias sobre o materialismo histórico para o plano da arte, observa-se que Brecht e Claudel extraem suas reminiscências do passado histórico e as transforma em "alegorias históricas", não hesitando em demonstrar os diversos discursos ideológicos que ficaram marcados sobre o cenário histórico em que viveu a virgem francesa. É neste sentido que o processo de desmistificar torna-se também um processo de recriar. 
O mais importante no trabalho de criação artística por meio da investigação das reminiscências passadas é a possibilidade de representá-las de acordo com os sentidos do tempo presente, capazes de renovar os diálogos com o passado. Num estágio posterior é a própria recepção que "manipula" a narrativa parabólica, recriando os seus sentidos.

Ao que tudo indica, a possibilidade da construção do texto teatral através de parábolas começa a tomar corpo com a decadência do drama burguês e a ascensão das novas experiências teatrais construídas ao longo do século passado. Esta "migração," no entanto, não é gerada espontaneamente, ela é diretamente impulsionada por questões sociais e pelos processos industriais que levaram a sociedade a agir de acordo com um modelo de coletivização, tipificação e massificação, onde o homem passa a identificar-se com a sua função, seja ela individual ou coletiva. Estas relações sociais, fornecedoras de substância para as criações teatrais acabaram por articular uma nova forma de trabalhar com a ação teatral, principalmente em relação ao tratamento dado aos diálogos e aos personagens. No entendimento de Gerd Bornhein quando o eu burguês entra em decadência: "o indivíduo cede o seu lugar ao tipo: ele é o soldado, o amante, a vítima. Toda realidade pessoal como que se cristaliza em títulos estereotipados" (BORNHEIN, 1992, p. 26).

O personagem tipo é o modelo ideal para a construção parabólica. Ele compõe a alegoria e o arquétipo, que são os veículos dos textos parabólicos. Joana d'Arc nas três peças não é mais a virgem de Orleans, é um arquétipo da feminilidade, das lutas sociais, do sacrifício pessoal em benefício da coletividade. Outros personagens como os representantes do poder econômico, político e religioso, também podem ser configurados como tipos alegóricos dentro das três peças.

Os autores compõem com suas "Joanas" um gigantesco labirinto onde desfilam tipos que dialogam com as inúmeras ideias relacionadas ao mito. Tais ideias não se fecham em si mesmas, nem tampouco dependem de um dimensionamento psicológico para sobreviverem, comportando-se como quadros vivos passíveis de serem manipulados pelos espectadores conforme o seu entendimento.

Mesmo partindo de pontos de vista por vezes opostos, os dois autores compartilham do desejo de traçar em suas peças uma trajetória de significados que aos poucos vai sendo descoberta e interpretada pelo leitor-espectador. Este modelo considera que a forma de contar revela-se tão importante quanto o fato contado e, dependendo dos ingredientes de atração usados nesta narrativa, pode-se compor um amálgama de sentidos que não se fecha em nenhuma conclusão definitiva.

A substância ideológica, o plano da moral ou da lição que compõe a parábola, tanto em Claudel quanto em Brecht encontra-se sempre em estado de "latência" e nunca é apresentada diretamente dentro de suas peças. Ao mesmo tempo ela é sempre testada e contraposta de diferentes formas, que se deslocam e transitam, variando inclusive de gênero. Assim se estabelece uma "tensão entre a metáfora e o documento" (SARRAZAC, 2002, p. 1), num jogo interminável em que a criação narrativa que faz uso de formas que seduzem o leitor-espectador - repleta de insinuações, simbolismos e brincadeiras - ao mesmo tempo atira em sua face a crueza da realidade. Neste jogo não há espaço para pontos de vista parciais ou manipuladores por parte dos autores, considerando que as relações de todas as ordens são simplesmente apresentadas e compartilhadas com o leitor-espectador, que deve refletir sobre o que leu ou viu. 
O mito de Joana d'Arc é configurado pelos autores sob uma ampla teia de significados, que não se prendem a moldes fragmentados nem tampouco compartimentados, ultrapassando o plano histórico e estendendo-se pelos planos ontológicos, psicanalíticos, culturais e sociais, ao ponto de desmembrar-se em outras interpretações e reflexões que estão longe de uma visão dualista de sentido. No entendimento do filósofo Gilles Deleuze: "as coisas e as proposições acham-se menos em uma dualidade radical do que de um lado e de outro de uma fronteira representada pelo sentido" (DELEUZE, 1994, p. 37).

Tanto Brecht quanto Claudel lançam mão dos mais diversos e ousados experimentos formais para o tratamento da ação. Utilizam-se provérbios, versos, coros e outros tipos de falas artificialmente concebidas para determinados personagens como, por exemplo, a linguagem do sonho de As Visões de Simone Machard, o uso de sotaques diferentes em Joana d'Arc entre as Chamas e a fala agressiva e artificial dos personagens de Santa Joana dos Matadouros.

Os autores trabalham com os recursos formais de maneira que, independentemente do conteúdo abordado nas peças, possam descrever críticas e insinuações. Por exemplo, apenas através da entonação das vozes de dois personagens do folclore francês: "Rompe-Vento" e "Mãe-Pipa" - que falam com sotaques das cidades francesas de Picardia e Borgonha - Claudel descreve a rivalidade entre as duas cidades, lançando sua crítica sobre a desunião dos habitantes destas cidades em face da invasão estrangeira em todo o território francês. Ao mesmo tempo, qual seria a real mensagem contida na utilização por Claudel de três línguas diferentes dentro da peça: o francês, o latim e o inglês? Será possível existir algo por trás do fato do latim ser a língua oficial da igreja católica e o inglês ser a língua do país que invadiu a França?

Já o uso que Claudel faz dos efeitos sonoros, não se limita a dar ênfase aos momentos de tensão da peça. Estes efeitos apresentam quase a função de um personagem: aquele que avisa, que dimensiona e que por vezes incomoda e amedronta o leitor-espectador, como as vozes e os sons soturnos que acompanham o suplício de Joana d'Arc em Joana d'Arc entre as Chamas. Em Santa Joana dos Matadouros, o cântico dos representantes do Exército da Salvação - os Boinas Pretas - demonstram a intenção de seu autor de ridicularizar e desmascarar a hipocrisia das instituições religiosas. Por outro lado o tambor de Simone em As Visões de Simone Machard, possui a função de tirar a ação de dentro para fora, ou, em outras palavras de convocar o público mesmo, fazendo-o sentir-se parte da luta. Para compor seus personagens, os dois autores lançam mão do desenho de máscaras. Em Brecht, os personagens não são humanos, são todos caricaturas, representam um tipo de conduta social. Por outro lado, Claudel as utiliza declaradamente na cena do julgamento de Joana em que os juízes, o júri, os promotores e defensores utilizam máscaras de animais.

A parábola em Claudel e em Brecht se faz presente não somente em relação ao tratamento dado aos temas - onde a verdade concreta é substituída por uma verdade fantasiosa, mas também se torna disfarce por meio das formas com que são apresentadas, levando em conta que estão claramente configuradas no texto e ganham maior expressão ainda, quando inseridas nos limites do palco.

Os autores fazem ainda uso da construção de "quadros autônomos" que se apresentam cada um com uma significação própria, como se em cada quadro fosse discutido um assunto que não se opõe ao assunto seguinte.

Paul Claudel classifica sua peça como oratório dramático. Ela se desenvolve 
desde a narrativa dos últimos acontecimentos que levaram Joana até a fogueira. Trata-se do processo de Joana d'Arc lido por Frei Domingos.

Inspirado pela filosofia tomista o autor francês acredita que diante da eternidade todos os conflitos humanos perdem importância, no entanto lida com os seus pontos de vista filosóficos e ideológicos de forma indireta e aberta quando os insere na sua criação dramatúrgica. Isto significa que mesmo acreditando na providência divina o autor não fecha os seus conceitos, nem suas expectativas diante das coisas do mundo, discutindo ainda em suas peças as relações entre o poder, as elites e os estratos inferiores, e mesmo acreditando que a maldade é inerente ao ser humano, não ignora os aspectos concretos das relações humanas. Assim, ao leitor-espectador é dada ainda a oportunidade de saber que Joana d'Arc lutou não pela França dos ricos senhores feudais, mas pela França dos fracos e oprimidos, o que não é discutido em termos históricos. Para tanto, Claudel apresenta o rei francês - que assim como Joana é um personagem histórico - como um egoísta cujo interesse na luta contra a invasão inglesa se resumia em preservar o privilégio dos ricos e poderosos e não demonstrava qualquer interesse pela integridade nacional francesa.

Por revelar-se sempre sob forma de alegoria, portanto sem nenhum compromisso com a verdade real, os conteúdos ideológicos em Claudel são testados e contrariados o tempo todo. Sua visão teocêntrica do mundo não impede a exposição das relações de ordem social, o que nos leva a crer que o autor não se aliena dos problemas reais do seu tempo, ainda que tente continuadamente buscar uma solução providencial para estes problemas.

Na quarta cena de Joana d'Arc entre as Chamas, Joana d'Arc é submetida a um julgamento em que os acusadores usam máscaras de animais numa clara menção aos diversos cargos de poder com todas as suas prerrogativas. Nesta cena fica claro que a estes "juízes" não interessa julgar a acusada ou quem quer que seja que não possua nem o poder político nem o poder econômico. Sendo assim, Joana já se encontra antecipadamente condenada e o julgamento não passa da encenação de um grande teatro de máscaras.

Para o autor francês a mulher é a representação da alma humana e é, portanto, o cerne de sua inquietude religiosa e igualmente de sua criação teatral. Claudel transfere para o teatro o percurso intelectual de sua criação dramatúrgica, onde se opera um constante processo de construção e reconstrução, que se refere tanto aos seus temas quanto às suas formas, e como para Claudel: "tudo que é perecível é apenas um símbolo do eterno" (ROSENFELD, 1985, p. 136), sua Joana histórica de carne e osso, deve simbolizar as coisas eternas da humanidade.

Os elementos de tensão e dramaticidade em Joana d'Arc entre as Chamas são despertados pelas vozes corais que compõem algumas cenas com o intuito de dar dinamismo e expressividade aos embates filosóficos propostos pelo autor. Entretanto estas vozes corais não se envolvem com os conflitos pessoais da protagonista. As palavras proferidas por estas vozes são muitas vezes as mais cruéis possíveis, mas na peça, nem Joana nem seus defensores reagem com emoção em relação a elas. É interessante pensar em como o autor francês desassocia a emoção dos conflitos pessoais, mas, em contrapartida, a relaciona às formas de comunhão e celebração.

No teatro de Brecht, os personagens vivenciam determinado conflito emocional, contudo, na cena seguinte se revelam sem qualquer ranço emocional do conflito passado na cena anterior. Percebe-se que cada personagem tem um objetivo a se- 
guir dentro das peças e o autor não perde tempo em explicar para o leitor-espectador todas as razões dos conflitos pessoais anteriores de seus personagens.

Em As Visões de Simone Machard, a protagonista descrita por Brecht é uma adolescente que trabalha como garçonete numa hospedaria francesa, prestes a ser invadida pelas forças nazistas. Ao ter acesso a um livro sobre a história de Joana d'Arc Simone vai aos poucos deixando de pensar como uma adolescente comum e começa a tecer questionamentos, se posicionando politicamente diante dos efeitos da guerra.

Após sucessivos sonhos com a heroína francesa, Simone resolve ajudar os refugiados pobres de uma França prestes a ser invadida pelos alemães na Segunda Guerra Mundial. Seu último ato heróico é atear fogo no tanque de petróleo de seu patrão para impedir que os alemães destruam a cidade, mas é denunciada pelo próprio patrão, que tinha negócios com o inimigo, sendo presa e enclausurada como louca num convento de freiras para toda a vida.

Como muitas outras meninas de sua idade Simone é uma adolescente tímida, apaixonada, retraída e suas fragilidades, defeitos e qualidades são expostos de forma realista, sem truques ou efeitos formais. Não obstante, pouco a pouco a consciência da guerra ultrapassa os interesses frugais de uma menina adolescente e Simone se transfigura na guerreira Joana d'Arc, armando estratégias e discutindo com chefes de Estado, ações que na realidade não condizem com a maturidade de uma menina de catorze anos. Brecht trabalha no limite da transformação da personagem real e humana, até a sua total transfiguração numa personagem arquetípica e alegórica.

Em Santa Joana dos Matadouros a personagem principal chama-se Joana Dark (em inglês), uma missionária do Exército da Salvação, cuja missão é tentar negociar os conflitos de ordem econômica entre a massa trabalhadora e os seus patrões, magnatas da indústria de carne em plena crise econômica americana de 1929. Ao tomar conhecimento das negociatas entre os produtores, industriais e comerciantes da carne - que visam somente o lucro através da exploração da mão-de-obra humana, ela passa a entender que a providência divina não é a verdadeira responsável pelo desemprego e pelos baixos salários dos trabalhadores da fábrica de enlatados.

A transformação de Joana D'arc também não é imediata, aos poucos ela vai entendendo o funcionamento do sistema e muitas vezes volta atrás acreditando que a religião pode resolver tudo e que a falta de sorte de muitos é propiciada pelas forças ocultas do destino. O desenvolvimento da peça vai aos poucos sugerindo a "substituição da caridade pela euforia intelectual e pelo sarcasmo" (SCHWARZ, 1990, p. 10).

A peça ilustra como a organização religiosa intervém na luta de classes para esvaziá-la. Para expor esta problemática, Brecht se aproxima do mito de Joana D’Arc e demonstra a transformação da Santa Joana, que se rebela contra as instituições religiosas, deixando de ser uma líder para se tornar uma mártir: ao final ela é usada a favor dos magnatas da carne e contra os trabalhadores.

Os autores revelam dentro das três peças os seus desejos concretos de transformação e de revolução fazendo uso de construções alegóricas e metafóricas onde se opera um desvio da mensagem concreta e convencional. Estes desejos nunca são inteiramente desvelados, mas são constantemente sugeridos. Deste modo, é possível concluir que o desejo que impulsiona Claudel e Brecht provém do princípio "deleuzeano" de desejo, em que nenhuma ação é espontânea ou aleatória, mas mantém estreitas relações com a história. Todavia, este mesmo desejo se associa à vontade e ao sonho, e, neste sentido, sua forma não deve condizer com o realismo ou o naturalismo. 
Nos limites deste estudo conclui-se que seja ponto pacífico na obra de Brecht e na obra de Claudel que os indivíduos e as relações individuais não sejam valorizados. Tanto Brecht quanto Claudel seguem o modelo de arte pensado por Deleuze, "que possui um olho que não pára nos indivíduos, mas vai aos acontecimentos puros e aos devires que estão em pauta nas coisas e nas pessoas" (ALMEIDA, 2003, p. 119). Ainda que Brecht possua uma visão social e Claudel possua uma visão cósmica do mundo.

Quando Claudel deixa os seus personagens à mercê da vontade divina, eles parecem se tornar independentes da ordem autoral, não são mais comandados pelos princípios morais do seu autor e isto, por ironia, ocasiona que as relações entre os personagens ganham também contornos sociais e não se limitam ao discurso primordial do seu autor.

Em contrapartida, com Brecht as relações sociais se tornam independentes dos princípios morais do autor, dentro dos limites próprios das relações sociais que é o cerne do seu interesse dramatúrgico. Estes mecanismos são construídos desde o instante em que o foco da ação se desloca do indivíduo. Para tanto, os autores precisam fazer uso da verossimilhança como convenção, ou seja, convenciona-se que tudo seja uma verdade simbólica e não mais a verdade realista dos conflitos individuais. E é neste momento que a parábola se torna uma alternativa considerável, pois possibilita a verossimilhança como convenção. No caso dos dois autores as relações temáticas e formais são conduzidas o tempo todo, por intermédio da narrativa parabólica, para fora do seu eixo central. Quando os conteúdos ideológicos são configurados, as formas utilizadas se desviam dos seus caminhos convencionais e vice-versa. De tal modo, mesmo que as visões de abordagem sobre o mundo nos dois autores possuam diferenças entre si, elas encontram um lugar comum, o desvio parabólico. Este mecanismo ocasiona um movimento dialético, propondo que a mensagem se estenda para além da significação imediata, gerando na recepção um pensamento marcado pela autonomia, que se reconstrói e se reinventa constantemente.

\section{Referências}

ALMEIDA, Júlia. Estudos deleuzeanos da linguagem. Campinas, SP: Editora da UNICAMP, 2003.

BENJAMIN, Walter. Magia e técnica, arte e política. Tradução de: Sergio Paulo Rouanet. São Paulo: Editora Brasiliense, 1985.

BRECHT, Bertolt. Santa Joana dos Matadouros. Tradução e estudo introdutório: Roberto Schwarz. São Paulo: Editora Paz e Terra, 1990.

As visões de Simone Machard. Tradução de: Angelika E. Köhnke. In: Teatro Completo em 12 volumes. Rio de Janeiro: Paz e Terra, 1992.

BORNHEIN, Gerd. Brecht: a estética do teatro. Rio de Janeiro: Graal, 1992.

CLAUDEL, Paul. Joana d'Arc entre as Chamas. Tradução e Prefácio de: Dom Marcos Barbosa. Rio de Janeiro: Editora Agir, 1956. 
COSTA, Iná Camargo. Palestra Brecht e o Teatro Épico. In: Diálogos com Brecht. São Paulo: Revista Fábrica São Paulo, 2005.

DELEUZE, Gilles. Lógica do sentido. Tradução de: Luiz Roberto Salinas Fortes. São Paulo: Perspectiva, 1994.

JAMESON, Fredric. O método Brecht. Tradução de: Maria Sílvia Betti. Petrópolis, RJ: Editora Vozes, 1999.

LE GOFF, Jacques. Em busca da Idade Média. Tradução de: Marcos de Castro. Rio de Janeiro: Civilização Brasileira, 2005.

PAVIS, Patrice. Dicionário de teatro. Tradução de: J. Guinsburg e Maria Lúcia Pereira. São Paulo: Perspectiva, 1999.

RODRIGUES, Wilma. Santa Joana Segundo Seghers e Brecht. São Paulo: Editora HUCITEC, 1978.

ROSENFELD, Anatol. O teatro épico. São Paulo: Editora Perspectiva, 1985.

SARRAZAC, Jean-Pierre. La parabole ou l'enfance du théâtre. Belfort: Circe, 2002. Tradução livre de Walder Virgolino.

SUASSUNA, Ariano. Iniciação à estética. Rio de Janeiro: José Olympio, 2005. 